\title{
Familial Platelet Disorder with Associated Myeloid Malignancy
}

National Cancer Institute

\section{Source}

National Cancer Institute. Familial Platelet Disorder with Associated Myeloid Malignancy. NCI Thesaurus. Code C162696.

An autosomal dominant condition caused by mutation(s) in the RUNX1 gene, encoding runt-related transcription factor 1 . It is characterized by thrombocytopenia, abnormal platelet function, and a propensity to develop acute myeloid leukemia. 